\title{
TERAPIA ANTI-RETROVIRAL: FATORES QUE INTERFEREM NA ADESÃO DE CRIANÇAS COM HIVIAIDS
}

\author{
Antiretroviral therapy: factors interfering in the adherence of \\ children with HIV/AIDS
Terapia anti-retroviral: factores que interfieren en la adherencia de niños con VIH/SIDA

\author{
Ana Claúdia Feitosa ${ }^{1}$ \\ Luciene Miranda de Andrade ${ }^{4}$
}

Hérica James Acioly de Lima²

Eveline Pinheiro Beserra ${ }^{5}$

Joselany Afio Caetano ${ }^{3}$

\section{RESUMO}

0 objetivo deste estudo foi conhecer os fatores que interferem na adesão à terapêutica medicamentosa em crianças infectadas pelo HIV/AIDS, relatados por 12 cuidadores em um serviço de referência em AIDS, em Fortaleza-CE. Os dados foram obtidos mediante entrevista, e, com eles, foram apurados fatores que dificultaram a adesão terapêutica, evidenciando relatos referentes à apresentação da droga, horário da tomada do medicamento, efeitos colaterais, falta na distribuição de medicamento gratuito, dificuldade de acesso regular ao serviço de saúde e problemas financeiros. Constatou-se a importância de conhecer o contexto social no qual a criança está inserida e as dificuldades no uso dos anti-retrovirais para intervir de forma eficiente e possibilitar uma melhor qualidade de vida às crianças.

Palavras-chave: Resultado de Tratamento. Terapêutica. Síndrome de Imunodeficiência Adquirida. Educação em Saúde.

\begin{abstract}
This study aimed to get to know the factors that interfere in medication treatment adherence among children infected by HIV/ aids, as reported by 12 caregivers in a service reference to aids in Fortaleza/CE, Brazil. Data were collected through interviews, verifying factors that made treatment adherence difficult, evidencing reports about drug forms, time of medication intake, collateral effects, shortage in the free drugs distribution, difficulty to get regular access to the health service and financial problems. The importance was revealed of getting to know the social context the child is inserted in and the difficulties in the use of antiretroviral drugs, so as to intervene efficiently and permit a better quality of life for the children.
\end{abstract}

Keywords: Resultado del tratamiento. Treatment. Acquired Immunodeficiency Syndrome. Health education.

\section{Resumen}

La finalidad de este estudio fue conocer los factores que interfieren en la adherencia a la terapéutica medicamentosa en niños infectados por el $\mathrm{VIH} /$ sida relatados por 12 cuidadores en un servicio de referencia en sida, en Fortaleza-CE, Brasil. Los datos fueron obtenidos mediante entrevista, y, con ellos fueran apurados factores que dificultaron la adherencia terapéutica, evidenciando relatos referentes a la presentación de la droga, horario de la toma del medicamento, efectos colaterales, falta en la distribución de medicamento gratuito, dificultad de acceso regular al servicio de salud y problemas financieros. Se constató la importancia de conocer el contexto social en que el niño está inser tado y las dificultades en el uso de los anti-retrovirales para intervenir de forma eficiente y posibilitar una mejor calidad de vida a los niños.

Palabras clave: Treatment outcome. Terapéutica. Síndrome de Imunodeficiência Adquirida. Educación en salud. 


\section{INTRODUÇ̃̃O}

Desde o início da epidemia da AIDS até o final da década de 1980, pouco se podia fazer pelos doentes, porém, em 1991, quando surgiram os primeiros medicamentos Zidovudina (AZT) e Didanosina (DDI), e, posteriormente, em 1996, com a terapia anti-retroviral, conhecida como "coquetel", nova perspectiva e outra dimensão foram dadas à doença'.

Os anti-retrovirais atuam diretamente no processo de virulência na célula e, também, na replicação viral, fazendo com que a multiplicação do HIV seja reduzida; com isso, diminui-se a quantidade de vírus no organismo, retardando 0 desenvolvimento da doença. Cada medicamento age numa determinada etapa da reprodução do vírus, de modo a impedir sua replicação nas células de defesa CD4 e a perder sua capacidade detectável ${ }^{1}$.

É nítido o avanço no tratamento dessa doença, pois, com o advento dos anti-retrovirais no tratamento da AIDS, observouse uma melhora significativa na qualidade de vida dos pacientes. Com isto, a AIDS passa a ter características de uma doença crônica. Mas, apesar do grande benefício gerado por esta terapêutica, restam ainda muitas dificuldades a serem superadas. Uma delas é a adesão do paciente ao seu tratamento.

A experiência desenvolvida no atendimento a pessoas soropositivas, desde 1996, revela um crescimento na demanda de atendimento a crianças. Essas evidências apontam novos e crescentes desafios para a equipe multiprofissional que assiste essa clientela infantil, pois dúvidas, dificuldades e preocupações surgem sobre a adesão ao tratamento.

Como observado, o manejo da infecção por HIV em crianças está evoluindo rapidamente e se torna cada vez mais complexo. Isso se deve ao fato de que o tratamento adequado de lactentes, crianças e adolescentes com HIV exige considerações sobre diversos fatores específicos a essas populações, inclusive diferenças na farmacocinética dos medicamentos e nos marcadores virológicos ou imunológicos em comparação aos outros pacientes, além de questões de adesão relacionadas à idade ${ }^{2}$.

Um fator fundamental para a eficácia do esquema terapêutico é a adequada adesão ao tratamento por parte da criança e dos responsáveis. Na escolha do regime anti-retroviral, devem ser levados em conta os principais fatores que influenciam na adesão: disponibilidade e palatabilidade da formulação; impacto do esquema terapêutico na qualidade de vida, incluindo número de medicamentos, freqüência de administração e necessidade de ingestão com ou sem alimentos; habilidade dos responsáveis na administração de regimes complexos; potencial de interação com outras drogas e efeitos colaterais. Recomenda-se, dentro das possibilidades de cada serviço, a formação de grupos multidisciplinares dedicados a facilitar a adesão por parte dos pacientes e cuidadores ${ }^{3}$.

Entre os problemas relacionados à adesão dos pacientes ao tratamento, sobressai a baixa adesão aos anti-retrovirais, a qual pode repercutir negativamente em três dimensões: em relação ao paciente, por prejudicar a resposta à terapêutica e conseqüentemente a evolução clínica da doença; na equipe de saúde, pois interfere na avaliação dos resultados, gerando frustração e até diminuição do investimento da equipe no paciente; e no sistema de saúde, que pode levar o paciente a submeter-se a procedimentos diagnósticos e terapêuticos desnecessários e de custos altos ${ }^{1}$.

Diante destas considerações, percebe-se a necessidade de realização desse estudo, cujo objetivo foi conhecer os fatores que interferem na adesão à terapêutica medicamentosa em crianças infectadas pelo HIV/AIDS. De modo geral, no Brasil, pouco se conhece sobre as dificuldades e os fatores adversos que estão afetando as crianças com HIV/AIDS e suas famílias, apesar de esforços para a sistematização de experiências relativas ao atendimento institucional a essa clientela empreendidos por organizações da sociedade civil, muitas delas com apoio governamental e de agências internacionais ${ }^{4}$.

Portanto, a relevância deste estudo justifica-se em face da urgência de se conhecer melhor os fatores que interferem na adesão à terapêutica medicamentosa em crianças infectadas pelo HIV/AIDS a partir dos cuidadores, com vistas a uma melhor adesão, entendida aqui como a utilização dos medicamentos prescritos ou outros procedimentos em pelo menos $80 \%$ do seu total, observando horários, doses e tempo de tratamento ${ }^{5}$.

\section{METODOLOGIA}

Estudo exploratório e descritivo, com abordagem qualitativa. Cabe ao pesquisador no estudo descritivo observar, descrever e documentar os aspectos de determinada situação ou fenômeno, sem se preocupar em estabelecer relações de causa e efeito 6 . 0 estudo exploratório e descritivo tem o objetivo de proporcionar uma visão geral de tipo aproximativo, sobre determinado fato, consistindo na análise e descrição de caraterísticas?.

0 cenário da pesquisa foi o ambulatório do Hospital Público de Doenças Infecciosas no Estado do Ceará, referência no atendimento de indivíduos portadores de HIV/AIDS. Participaram do estudo 12 cuidadores de crianças, responsáveis pelo acompanhamento nesta instituição, e adotaram-se como critérios de inclusão aceitação em participar da pesquisa no período da coleta de dados, ocorrida no mês de abril de 2006, e existência de condições psíquicas para poder fornecer informações ao pesquisador.

Foi elaborado um roteiro de entrevista semi-estruturado, previamente testado para adequação quanto à linguagem, seqüência e clareza das questões, abordando os seguintes aspectos: o nível socioeconômico do cuidador da criança; a caracterização das crianças com HIV/AIDS e questões sobre os fatores que interferem na adesão ao tratamento anti-retroviral pelos cuidadores.

Conforme recomendado, esta pesquisa foi submetida à Comissão de Ética e Pesquisa do Hospital do referido estudo e aprovada, seguindo as exigências do Conselho Nacional de Saúde - Ministério da Saúde, de acordo com a Resolução 196/ $96^{8}$ do Conselho Nacional de Saúde/Ministério da Saúde, que 
dispõe sobre a pesquisa referente a seres humanos, quais sejam: autonomia, liberdade, não-maleficência e justiça.

Quando abordados, os sujeitos da pesquisa foram esclarecidos sobre o objetivo do estudo, com destaque para o sigilo e a confidencialidade das respostas direcionadas ao instrumento. Após aceite, procedeu-se à assinatura do Termo de Consentimento Livre e Esclarecido (TCLE), protocolo no. 040/2005.

Os dados foram analisados a partir dos depoimentos dos sujeitos, com base na técnica da análise de conteúdo ${ }^{9}$, que confere a melhor forma de investigação e de tratamento das mensagens obtidas, pois, em decorrência das vantagens, possibilita apreender idéias subjetivas dos sujeitos entrevistados vinculadas às suas crenças, valores e opiniões.

De posse dos dados, estes foram organizados em consonância com as seguintes etapas: a pré-análise, a exploração do material e o tratamento dos resultados, a inferência e a interpretação. Segundo a literatura, a utilização dessa técnica consiste na explicitação e sistematização do conteúdo das mensagens e da expressão deste conteúdo ${ }^{9}$. Na apresentação dos resultados, para manter o anonimato, as falas dos sujeitos estão identificadas com a inicial do cuidador, seguida do número da participação da pesquisa, e sua interpretação apoiou-se na literatura pertinente.

\section{RESULTADOS E DISCUSSÕES}

Diante do número de casos existentes de crianças e adolescentes convivendo com o vírus do HIV, é fundamental compreender a realidade vivenciada por eles para aprimorar a atenção à saúde prestada.

\section{Perfil demográfico e socioeconômico dos cuidadores das crianças com HIV/AIDS}

Neste estudo, o cuidador é visto como o familiar responsável pelos cuidados às crianças infectadas pelo vírus HIV/AIDS. Estes disponibilizam parte do seu dia a cuidar destas crianças. Para que as orientações dos profissionais de saúde sejam voltadas para a realidade social dos cuidadores, ou seja, baseadas em suas condições socioeconômicas e culturais, é preciso conhecêlos. Um indivíduo ou um grupo não pode ser analisado isoladamente da sua realidade cultural e socioeconômica, pois o comportamento humano está condicionado por esses fatores que demonstram os riscos e agravos à sua saúde ${ }^{10}$.

A assistência no âmbito domiciliar requer muita informação sobre o tratamento da doença, riscos de contágio e, também, sobre dificuldades emocionais e preconceitos advindos. Embora, normalmente, a família não esteja preparada para conviver com a doença, é preciso orientá-la, e isso envolve aspectos biológico, social, emocional e espiritual.

Foi identificado que o sexo feminino predomina nos cuidadores diretos da criança. Desde os primórdios da humanidade, o cuidado é realizado pelas mulheres, e, por meio desse cuidar, elas estabelecem uma forma de relação com 0 mundo ${ }^{11}$.
Quanto à idade dos cuidadores, no estudo foi observado o seguinte: quatro estavam na faixa etária dos 33 aos 37 anos, e dois, dos 17 aos 22 anos. Portanto, são cuidadoras jovens com grande responsabilidade para cuidar de uma criança infectada pelo HIV. As principais cuidadoras são as mães (cinco); avós (três); pai (dois); e os parentes próximos, como irmã (dois). 0 cuidador principal é a mãe, que se define como a pessoa da família com o dever moral de ficar com a criança e se sente na obrigação de cuidar do filho, uma vez que a própria criança a elege como protetora dentre os outros familiares; ela acredita que ninguém está à altura de, como ela, cuidar e proteger o seu filho ${ }^{12}$.

Todos os cuidadores possuem baixo nível de escolaridade; seis $(50 \%)$ estavam no ensino fundamental. Este fato está de acordo com outros estudos ${ }^{11,13}$, que revelam a condição de pauperização, vulnerabilidade social e grau de instrução limitado dos entrevistados como fatores que dificultam 0 processo de educação em saúde no cuidado especial a essas crianças com HIV.

No Brasil e no mundo, a AIDS pode ser considerada um problema social que atinge, sobretudo, as classes mais pobres e desfavorecidas, uma vez que o perfil epidemiológico desta doença tem sido caracterizado por uma intensificação dos processos de feminização, heterossexualização, interiorização, pauperização e juvenização. Ou seja, cada vez mais as notificações registram um aumento no número de mulheres heterossexuais infectadas, particularmente em cidades de pequeno e médio porte no interior do país, com baixos níveis de escolaridade e renda, e na idade reprodutiva. Isto faz aumentar os casos de crianças com HIV ${ }^{14}$.

De acordo com os dados, a renda familiar dos cuidadores do estudo variou da seguinte forma: três recebiam até um salário mínimo; três, entre um e dois salários; quatro não recebiam nenhum tipo de renda. Portanto, as famílias possuem baixo poder aquisitivo. 0 baixo nível socioeconômico dos cuidadores interfere na qualidade de vida destas crianças, pois os gastos financeiros decorrentes da doença são bastante altos. Tais gastos incluem despesas com transporte, medicamentos e principalmente com a alimentação, já que as crianças necessitam de uma alimentação rica, com frutas, verduras, sucos, para se reduzirem os riscos de infecção ${ }^{15}$.

Além destas dificuldades, a adesão, entendida como utilização adequada dos medicamentos e do cuidado de saúde como um todo, é afetada pelo âmbito social e cultural onde acontece, como também pela influência social, caracterizada pela faixa salarial e escolaridade ${ }^{5}$.

\section{O perfil das crianças com infecção pelo HIV}

No perfil das crianças, observou-se que houve a mesma proporção entre o sexo masculino e o feminino, seis. Em relação à idade, a faixa etária predominante foi entre os 5 e os 9 anos. Quanto à forma de transmissão predominante, foi a vertical. Este dado se correlaciona com a maior incidência de infecção pelo HIV em mulheres, quer pelo uso das drogas quer pelo contato sexual com parceiros HIV-positivos. 
Das doenças relatadas pelos cuidadores, as principais foram as do aparelho respiratório, como pneumonia, gripes, os distúrbios gastrointestinais, como diarréia, alterações dermatológicas e deficiências nutricionais.

Essas doenças são bastante comuns no período da infância, e podem levar muitas vezes ao retardamento do diagnóstico. Em muitas famílias, o diagnóstico de infecção pelo HIV ainda é feito a partir do adoecimento da criança. Entretanto, o aumento da longevidade e a melhora da qualidade de vida das crianças infectadas dependem, fundamentalmente, do diagnóstico precoce e do adequado tratamento da infecção.

Alguns sinais, porém, são evidentes no caso de AIDS em criança. De acordo com o Ministério da Saúde ${ }^{3}$, os principais sinais clínicos que acometem os pacientes pediátricos com AIDS são: diarréia crônica, tuberculose, herpes e candidíase oral resistente. Os sinais menores são: febre constante, perda de peso, otite, sinusite, dermatite, alterações do sistema linfático ou hepático (anemia, linfopenia, trombocitopenia, hepatoesplenomegalia). Outros indicativos observados em crianças infectadas são: desnutrição, pneumonias, toxoplasmose, aparecimento de manchas de sangue na pele (sarcoma de Kaposi) e comprometimento neurológico (neurossífilis e encefalopatias, e déficit no desenvolvimento neuropsicomotor) ${ }^{3}$.

\section{Fatores que interferem na adesão ao tratamento pelos cuidadores de crianças portadoras de HIV/ AIDS}

Dos itens relatados pelos cuidadores sobre as dificuldades relacionadas à adesão dos anti-retrovirais, a partir de suas falas, originaram-se seis tópicos que descrevem esses fatores: apresentação da droga, horário da medicação, falta na distribuição de medicamentos gratuitos, efeitos colaterais das drogas, dificuldade de acesso regular ao serviço de saúde e problemas financeiros.

A cronicidade da AIDS implica a adesão a um regime medicamentoso completo e prolongado. Conforme demonstrado por estudos, falhas na adesão aumentam o risco de incompleta supressão viral e de desenvolvimento de cepas virais resistentes aos medicamentos disponíveis ${ }^{16,17}$. Diante de situações difíceis de lidar relativas ao tratamento e a aspectos do cotidiano, os cuidadores primários - muitos deles também soropositivos adotam estratégias de enfrentamento diversas, com vistas ao bem-estar físico, psicológico e social das crianças ${ }^{18}$.

Com 0 advento dos anti-retrovirais, houve uma melhora significativa na qualidade de vida dos pacientes; entretanto, muitas dificuldades surgem na administração da medicação, 0 que prejudica o êxito no tratamento. Fatores como a quantidade de medicamentos, reações adversas, necessidade de períodos de jejum, incompatibilidade entre as drogas, dificuldade na compreensão das metas da terapia e da implicação do seu uso inadequado, contribuem para comprometer o processo terapêutico.

Assim, as orientações medicamentosas devem ser direcionadas ao cuidador da criança, para que seja responsável pela administração da terapêutica medicamentosa. Contudo, 0 êxito do tratamento depende da correta compreensão do tratamento, pois a não-adesão é uma das responsáveis pela piora do quadro clínico e, conseqüentemente, por maior dano à saúde do paciente ${ }^{19}$.

A adesão a um regime terapêutico requer da pessoa mudanças no seu estilo de vida para realizar atividades específicas que promovam e mantenham a saúde. Essas atividades envolvem tomar as medicações prescritas regularmente, manter uma dieta, automonitorar os sinais e sintomas da doença e submeter-se a avaliações de saúde periódicas.

De modo geral, as crianças fazem uso de três drogas antiretrovirais. A apresentação da medicação, como informado pelos cuidadores, é oral. Algumas são em comprimido, outras em suspensão ou pó para reconstituição, e a criança deve tomála até três vezes ao dia. Às vezes, como mostram as falas dos cuidadores, a forma de apresentação da medicação dificulta a administração:

Era líquido e passou pra comprimido. Ela reclamava que o remédio era ruim, mas depois se acostumou. C.7.

Era comprimido dissolvido no leite, ... e o médico mudou pra líquido. C 11.

[...] A quantidade de remédio também influencia. Ela toma $23 \mathrm{ml}$ de estavudina pela manhã e à noite[...]C.4.

Não, não gosta, ela vomita, mesmo fazendo uso de doce na hora que dou o remédio. C.6.

[...] No início ele dizia que era ruim demais, chorava, mas eu dizia que tinha que tomar para ficar bonzinho. A apresentação do pó dificulta, pois é dado no leite e ele não gosta do sabor. C.9.

Observa-se que outro aspecto é a questão do gosto dos remédios. Em virtude de as indústrias farmacêuticas não produzirem medicações voltadas, exclusivamente, para atender essa faixa etária, prejudica-se a adesão por parte das crianças.

Essas informações confirmam o mencionado pelo MS 20:41:

Além disso, os poucos medicamentos que existem em formulações líquidas ou em pó para crianças não são práticos de serem usados: uma criança tem que tomar três quantidades diferentes de três xaropes diferentes, na maioria das vezes intragáveis. Alguns medicamentos necessitam de refrigeração, outros de água potável, requerimentos estes nem sempre disponíveis em lugares empobrecidos, como favelas ou áreas rurais isoladas.

$\mathrm{Na}$ ausência de medicamentos adaptados às crianças, os cuidadores trituram, dissolvem a medicação antes de oferecer 
a elas. A adesão pode ser comprometida também pelo "esquecimento" de administrar o medicamento. Este é o motivo mais freqüentemente apontado como causa da omissão de doses, sendo necessário o uso de lembretes para evitar erros na hora da administração do remédio. Observa-se isto nas falas:

[... embora eu anote na porta da geladeira a receita ainda tenho dificuldade em dar o medicamento no horário, pois às vezes tenho que sair ou mesmo esqueço, sem contar nos horários inconvenientes. (C.1)

[...] o mais difícil é quando ela está na escola, aí não tem jeito, o remédio é dado fora do horário, ou até mesmo eu esqueço de dar os ARV... (C.2)

é importante, mas também muito chato administrar medicamento todo dia [...] (C. 4)

Às vezes, porém, não é tanto o esquecimento, mas a nãoingestão do medicamento em outro ambiente, que não o doméstico, o que também leva à omissão da dose. Há, ainda, a interrupção em decorrência do incômodo causado pelos efeitos colaterais dos medicamentos, além da necessidade de mudança na rotina doméstica. Diante destes fatos, às vezes, é desgastante se preocupar em dar medicamento todo dia, conforme comentado por uma participante.

0 manejo dessas dificuldades induz os cuidadores a criar estratégias para facilitar a administração da medicação e minimizar os efeitos colaterais, os quais, geralmente, são gastrointestinais, como nos relatos abaixo:

Vômitos, principalmente quando está com a barriga vazia. (C.1)

Não sente nada; às vezes ele diz que sente 0 estômago doer, dar um embrulho, toma o remédio em jejum, mas depois que toma o leite, um suco, vai passando (C. 12)

Conforme se constatou, o número de medicamentos empregados por paciente, o efeito colateral das drogas, o grande volume dos comprimidos, os horários de utilização e o sabor desagradável estão associados diretamente à adesão à terapêutica. Assim, torna-se necessária a implementação de intervenções direcionadas a grupos específicos para propiciar a adesão do paciente à terapia medicamentosa ${ }^{21}$.

Para facilitar a administração dos medicamentos, a enfermeira deve elaborar um roteiro segundo a prescrição médica, no qual os medicamentos são associados aos horários de jejum, refeição, escola e sono, tudo com base na rotina da criança.

No Brasil, os medicamentos anti-retrovirais são dispensados gratuitamente. De acordo com os informantes, a farmácia do ambulatório sempre oferece os medicamentos anti-retrovirais. Mas faltam os medicamentos usados na profilaxia e para diminuir os sintomas das reações adversas. Nesse caso, os cuidadores precisam se deslocar às unidades básicas de saúde mais próximas de sua residência para adquiri-los. Portanto, embora no Brasil os medicamentos anti-retrovirais possuam dispensação gratuita, não conseguem atender às necessidades básicas dos portadores de HIV/AIDS, como mostra o comentário:

Oferece, mas às vezes falta a sulfa, então pego no posto, mas os anti-retrovirais nunca faltaram. (C.5)

Oferece, sempre tem quando venho pra consulta. (C.7)

Desse modo, tornam-se um entrave na adesão ao tratamento. Como se sabe, o custo mensal com os medicamentos é muito alto. Então, ter acesso gratuito à medicação é fator primordial para a adesão.

Outro fator primordial é a atuação da equipe multidisciplinar e sua responsabilidade conjunta na definição de estratégias terapêuticas e desenvolvimento de suporte ao longo do tratamento. A equipe exerce papel fundamental na manutenção da motivação do cliente, na comunicação e no acesso às informações de forma clara e simples ${ }^{22}$, já que a adesão é um caminho de várias vias.

Na melhora da adesão, a grande aliada é a assistência individualizada, na qual a relação enfermeira-cuidador-criança deve ser permeada por confiança, empatia, respeito, privacidade e atitudes positivas, tais como: determinação de metas flexíveis; utilização de termos simples; consideração do contexto social e não-realização de julgamentos morais.

Ainda como entrave ao tratamento, observa-se a dificuldade de acesso ao serviço de saúde em face da distância entre as residências dos usuários e o serviço de saúde. Muitos usuários são do interior, e isso os leva a passar por vários transtornos, como acordar muito cedo para conseguir o transporte, exporse a riscos nesse percurso, deixar os afazeres domésticos, inclusive os outros filhos, sob a responsabilidade de terceiros e sentir-se humilhados por depender da caridade de outros, consoante as falas:

[...] Venho no carro da prefeitura todo mês, mas às vezes venho até mais, depende da necessidade do médico. Saio de casa às 3 horas da manhã, fico o dia todo no hospital, aqui eles oferecem um lanche e a gente passa o dia. (C.1)

[...] Pra vir é muito difícil, vou à prefeitura, falo com assistente social, peço a um, a outro; hoje vim a pé, sou de Maranguape, vim até o anel viário, peguei uma carona e cheguei aqui.(C.12)

As passagens são dadas pela Secretaria de Saúde de Itarema, tanto a ida como a volta. Se tivesse lá no meu interior, para facilitar essas viagens... se tivesse esses remédios lá não teria a preocupação de vir pra cá $[. .].($ C.3)

Já é uma dificuldade, pois venho pela prefeitura, o prefeito bota a maior dificuldade, vive dizendo que é pra transferir para Barbalha, pois pra cá fica caro demais. Acho que mais dificulta é a distância e é muito dispendioso... A doutora me dá 2, 3 receitas pra não ter que vir todo mês, mas, por ela, eu viria todo mês, mas não tenho condições, só de passagem eu iria gastar mais de 200 reais. (C.4) 
Constatou-se, também, nas falas dos participantes, que a centralização do serviço de saúde complica a continuidade do tratamento, por existir somente um hospital receituários para no mínimo dois meses. Porém o adequado seria 0 acompanhamento da criança a cada mês, e, se possível, em um serviço próximo à sua residência, evitando os transtornos e o ônus gerado com o deslocamento ${ }^{23}$.

0 outro entrave para a adesão ao tratamento foi a carência de recursos financeiros, como citado nas falas:

[...] devia existir uma lei para facilitar a pensão para auxiliar na doença, eu sou viúva, tenho três filhos de menor e eu preciso [...] (C.1)

[...] 0 dinheiro não dá pra nada. Tem que ter muita fruta, verdura e isso eu ainda não posso dar pra ela. Uma cesta básica a cada mês ou pelo menos de dois em dois meses ajudaria muito [...](C10)

0 que dificulta é a falta de alimentação, só ela (mãe) quem trabalha. O dinheiro é pouco, 190 reais, compro 1 lata de leite, só dá pra 1 semana. Se pudesse ter uma cesta básica pra nós [...] (C. 12)

Como mencionado, as famílias não têm condições de prover seus lares, principalmente com a alimentação e com gastos adicionais advindos da própria doença. Até os cuidadores citam como alternativa para suprir suas necessidades o fornecimento de uma cesta básica. A sugestão identificada nos resultados sobre a necessidade de criação de uma lei que facilite 0 recebimento dos direitos, sobretudo para aqueles portadores do HIV/AIDS e seus familiares, mostra a carência desta população. Em virtude de tal carência, as crianças sofrem a privação de alimentação, educação e outros cuidados indispensáveis.

Ainda como fatores importantes que podem influenciar na qualidade da adesão mencionam-se 0 acesso aos serviços de saúde e a estrutura à disposição do indivíduo. Conforme se observa nas falas, o serviço prestado pelo hospital é muito bom e, muitas vezes, chega até a ser melhor do que estar na própria residência. Pode-se concluir que as necessidades dos clientes são extremas, pois eles encontram no atendimento o preenchimento de suas carências, como alimentação, conforto e atenção. Entretanto, o serviço requer algumas modificações para favorecer a assiduidade dos clientes. Como os genitores das crianças atendidas também são portadores do vírus e precisam de acompanhamento mensal, poderiam se agendar as consultas de ambos para o mesmo dia. Desse modo, se evitariam os gastos financeiros adicionais e se reduziriam as faltas às consultas.

Urge reorientar a assistência com vistas a satisfazer as necessidades de saúde da clientela e a assistir a pessoa da maneira mais integral quanto possível - que ela seja ouvida e respeitada em sua singularidade. Para isto é relevante buscar incessantemente a compreensão do "momento atual", saber como se dá a assistência e em que concepções ela se fundamenta ${ }^{24}$. Desse modo, então, em outro momento, se poderá assistir o ser humano em toda sua humanidade.

\section{CONSIDERAÇÕES FINAIS}

Diante dessas considerações, conforme identificado, não há apenas um fator exclusivo a interferir na adesão à terapêutica medicamentosa. Os dados obtidos neste estudo apontaram para a existência de dificuldades na utilização do complexo esquema da terapêutica medicamentosa pelos cuidadores das crianças com HIV/AIDS. Tais dificuldades foram relativas ao efeito colateral das drogas, horário de administração dos medicamentos, acesso ao serviço e recursos financeiros limitados.

Constata-se que os profissionais envolvidos podem tentar compreender o contexto social no qual a criança está inserida para obter o êxito no tratamento, explorando dos cuidadores sua capacidade de cuidar apesar da diversidade dos problemas correlacionados. No processo saúde-doença da criança essa atitude é fundamental.

Como evidenciado, a indústria farmacêutica precisa investir mais em pesquisas para que novas formulações específicas e testes de diagnóstico sejam desenvolvidos no intuito de beneficiar essa clientela. A quantidade de medicamentos, a forma de apresentação e o gosto da medicação podem ser melhorados, pois influenciam na aceitação por parte da criança.

Outro ponto importante é criar estratégias para incentivar a adesão ao tratamento, como estudo de casos, oficinas interdisciplinares, grupos de adesão, com o objetivo de acolher o cuidador infantil, na perspectiva de fazer mudar sua condição, levando-o a se tornar sujeito do processo. Cabe também à enfermagem exercer sua ação junto a esse binômio cuidadorcriança, para proporcioná-lhes melhor qualidade de vida neste tratamento oneroso para ambos.

\section{Referências}

1. Narciso AMS, Paulilo MAS. Adesão e AIDS: alguns fatores intervenientes. Serv. Soc. Rev. Londrina 2001 jul/dez; 4(1): 27-43.

2. Oleske JM. Quando tratar as crianças com HIV?. J. Pediatr. (Rio J.) [periódico na Internet]. 2006 Ago [citado 2007 Out 04]; 82(4): 243-245. Disponível em: http://www.scielo.br/ scielo.php?script=sci_arttext $\&$ pid = S0021 $75572006000500002 \&$ lng $=$ pt\&nrm=iso.

3. Brasil, Ministério da Saúde. Guia de tratamento clínico da infecção pelo HIV. Brasília; 2004.

4.USAID/Partners of América/POMMAR. Vida que te quero viva! Sistematizando experiências apoiadas pelo POMMAR/USAID - Partners na área de atenção a crianças que vivem e convivem com o HIV e a AIDS. Brasília: USAID; 2004.

5.Leite SN, Vasconcelos MPC. Adesão à terapêutica medicamentosa: elementos para a discussão de conceitos e pressupostos adotados na literatura. Ciência e Saúde Coletiva 2003 jul/set 8 (3):775-781.

6.Polit DF, Beck CT, Hungler BP. Fundamentos de pesquisa em enfermagem. $5^{\mathrm{a}}$ ed. Porto Alegre (RS): Artmed; 2004.

7.Gil AC. Métodos e técnicas de pesquisa social. $5^{\mathrm{a}}$ ed. $7^{\mathrm{a}}$ reimpressão. São Paulo: Altas; 2006. 
8.Brasil CNS, Conselho Nacional de Ética em Pesquisa em Seres Humanos. Resolução no. 196 de 10 de outubro de 1996: diretrizes e normas regulamentadoras de pesquisas envolvendo seres humanos. 9.Bardin L. Análise de conteúdo. Lisboa (P0): Ed. 70; 2004.

10.Rouqueirol MZ, Goldbaum M. Epidemiologia, história natural e prevenção de doenças. In: Rouqueirol MZ, Almeida Filho N. Epidemiologia \& Saúde. 6ªed. Fortaleza: Medsi; 2003. p.17-23.

11.Padoin SMM et al. Perfil epidemiológico da criança com HIV/aids assistida no serviço de doenças infecciosas pediátricas do HUSM no período de 1999 a 2000. Saúde: Revista do Centro de Ciências da Saúde - UFSMS, Santa Maria, 28(12): jan/dez 2002.

12.Beck ARM, Lopes MHBM. Cuidadores de crianças com câncer: aspectos da vida afetados pela atividade de cuidador. Rev. Bras Enferm 2007 nov-dez; 60 (6): 670-675.

13.Gir E, Reis RK. Alterações no estilo de vida, necessidades e dificuldades enfrentadas pelos cuidadores de portadores de AIDS no âmbito domiciliar. Rev. Escola de Enferm USP 2001; 35(4): 328-35.

14.Schaurich D, Medeiros HMF, Motta MGC. Vulnerabilidade no viver de crianças com aids. Rev Enferm UERJ 2007 abr/jun; 15 (2): 28490.

15. Giugliani DFJ, Giugliani C. Alimentação da criança. In: Duncan BB, Schmidt MI, Giugliani ERJ et al. Medicina ambulatorial: condutas de atenção primária baseadas em evidências. $3^{\mathbf{a}}$ ed. Porto Alegre (RS): Artmed; 2004. p. 240-250.

16.Baer MR, Roberts J. Complex HIV treatment regimens and patient quality of life. Canadian Psychol 2002; 43: 115-21.
17.Murphy DA, Saar M, Durako SJ, Moscicki A, Wilson CM, Muenz LR. Barriers to Haart adherence among human immunodeficiency virusinfected adolescents. Arch Pediatr Adolesc Med 2003; 157: 249-55.

18.Klunklin P, Harrigan RC. Child-rearing practices of primary caregivers of HIV-infected children: an integrative review of the literature. J Pediatric Nurs 2002; 17: 289-96.

19.Sano PY, Masotti RR, Santos AAC, Cordeiro JA. Avaliação do nível de compreensão da prescrição pediátrica. J Pediatr 2002; 78(2): 140145.

20.Ministério da Saúde (BR) Secretaria de Vigilância Epidemiológica em Saúde. Departamento de Vigilância Epidemiológica. Doenças Infecciosas e Parasitárias: Guia de Bolso 6a Ed. Brasília (DF); 2005. P. 41

21.Figueiredo RM, Sinkoc VM, Tomazim CC, Gallani MCBJ, Colombrini MRC. Adesão de pacientes com AIDS ao tratamento com anti-retrovirais: dificuldades relatadas e proposição de medidas atenuantes em um hospital escola. Rev Latino-am Enfermagem 2001 jul; 9(4): 50-5.

22.Brambatti LP, Carvalho WMES. A adesão ao tratamento em pessoas vivendo com HIV/aids: barreiras e possibilidades. Rev Saúde do Distrito Federal $2005 \mathrm{jul} / \mathrm{dez}$; 16 (3/4): 25-30

23.Lima AC. Crianças com infecção pelo HIV: proposta de intervenção de enfermagem na perspectiva da Saúde Coletiva. [dissertação de mestrado]. Fortaleza (CE): Universidade Federal do Ceará; 1998

24.Nery TA, Tocantins FR. Atenção à pessoa com HIV em unidade básica: concepção acerca da assistência dos profissionais de saúde. Esc Anna Nery Rev Enferm 2005 abr; 9 (1): 88-94 